\title{
Classificação orientada a objeto (GEOBIA) aplicada à análise das alterações do uso e cobertura da terra da Bacia Hidrográfica do Rio da Prata em Jardim e Bonito - MS
}

\author{
Object-oriented classification (geobia) applied to the analysis of the alterations in the \\ use and cover of the land in Rio Da Prata watershed, located in the cities of Jardim \\ and Bonito (In The State Of Mato Grosso Do Sul - MS)
Clasificación orientada al objeto (Geobia) aplicada al análisis de las alteraciones del uso y la cobertura de la tierra de la cuenca hidrográfica del Río de La Plata en Jardim y Bonito-MS

\section{Laís Coêlho do Nascimento Silva ${ }^{1}$ Vitor Matheus Bacani ${ }^{2}$}

Recebido em 04/2017 - Aceito em 07/2017.

RESUMO: O presente estudo tem como objetivo analisar as mudanças no uso e cobertura da terra da bacia hidrográfica do Rio da Prata, MS, no período de 1986 a 2016, a partir da abordagem de classificação orientada a objeto (GEOBIA - Geographic Object-Based Image Analysis). Utilizaram-se as imagens Landsat 5, sensor TM (Thematic Mapper) para os anos de 1986, 1996 e 2006 e Landsat 8, sensor OLI (Operational Land Imager) para o ano de 2016. Aplicando técnicas de sensoriamento remoto e geoprocessamento, utilizou-se o software Envi 5.1 para a correção radiométrica e atmosférica e para classificação orientada a objeto: o Ecogntion 9, além do Arcgis 10.3. Foram definidas sete classes de uso da terra: agricultura, corpos aquosos, florestal, pastagem, áreas úmidas, vegetação arbórea e reflorestamento. Os resultados indicaram uma expansão agropecuária e consequentemente um decréscimo das áreas de vegetação arbórea. No período de 1986 a 2016 , a pastagem teve um aumento de 13,11\%, já as áreas de vegetação arbórea tiveram uma supressão de $21,37 \%$. Sendo assim, destaca-se a importância da análise do uso da terra, com auxílio do sensoriamento remoto e geoprocessamento, para indicar estratégias para ordenamento ambiental na bacia do Rio da Prata, MS.

Palavras-Chave: Uso do solo, Sensoriamento Remoto, Análise Espaço-temporal.

\begin{abstract}
This study aims to analyze the changes in the use and cover of the land in the Rio da Prata (MS) watershed from 1986 to 2016. The object-oriented classification (GEOBIA - Geographic Object-Based Image Analysis) has been adopted to that end. The Landsat 5 images, TM (Thematic Mapper) sensor, have been used for 1986, 1996 and 2006; and the Landsat 8 images, OLI (Operational Land Imager) sensor, for 2016. Remote sensing and geoprocessing techniques have been applied. The software Envi 5.1 was used for radiometric and atmospheric correction; and the Ecognition 9 and the Arcgis 10.3 programs, for object-oriented classification. Seven land-use classes have been defined: agriculture, water bodies, forest, pasture, humid areas, arboreal vegetation and reforestation. The results have evidenced an expansion of agriculture and cattle raising activities, with a consequent decrease in the arboreal vegetation areas. From 1986 to 2016, there was an increase of $13.11 \%$ in the pasture events. The arboreal areas, in turn, have suffered a reduction of $21.37 \%$. Therefore, it is important to analyze the land use, with the support of the remote sensing and geoprocessing resources, in order to indicate environmental planning strategies in the Rio da Prata watershed, located in Mato Grosso do Sul state.
\end{abstract}

Keywords: Land Use, Remote Sensing, Space-Time Analysis. 
RESUMEN: El presente estudio tiene como objetivo analizar los cambios en el uso y la cobertura de la tierra de la cuenca hidrográfica del Río de la Plata, MS, en el período de 1986 a 2016, a partir del abordaje de clasificación orientada al objeto (GEOBIA - Geographic Object-Based Image Analysis). Se utilizaron las imágenes Landsat 5, sensor TM (Thematic Mapper) para los años 1986, 1996 y 2006, y Landsat 8, sensor OLI (Operational Land Imager) para el año 2016. Aplicando técnicas de teledetección y geoprocesamiento, se utilizó el software Envi 5.1 para la corrección radiométrica y atmosférica y para la clasificación orientada al objeto: el Ecogntion 9, además del Arcgis 10.3. Se definieron siete clases de uso de la tierra: agricultura, cuerpos acuosos, forestal, pastura, áreas húmedas, vegetación arbórea y reforestación. Los resultados indicaron una expansión agropecuaria y, consecuentemente, una disminución de las áreas de vegetación arbórea. En el período de 1986 a 2016, la pastura tuvo un aumento del 13,11\%, mientras que las áreas de vegetación arbórea disminuyeron en un 21,37\%. De esta forma, se destaca la importancia del análisis del uso de la tierra, con ayuda de la teledetección y el geoprocesamiento, para indicar estrategias para el orden ambiental en la cuenca del Río de la Plata, MS.

Palabras clave: Uso del suelo, Teledetección, Análisis Espacio-temporal.

\section{INTRODUÇÃO}

A classificação orientada a objeto (GEOBIA) consiste na segmentação dos objetos da imagem, delimitando limites com regiões homogêneas, em vez de analisar os pixels independentemente de sua localização (DESCLÉE et al., 2006). De acordo com BLASCHKE et al. (2014) o GEOBIA é um paradigma em evolução, com ferramentas específicas, software, métodos, regras e linguagem, sendo cada vez mais usado para estudos que necessitam conceituar e formalizar conhecimentos.

Platt e Raposa (2008) afirmam que a classificação orientada a objeto tem um grande potencial para melhorar a precisão e classificação do uso da terra quando comparada ao método tradicional pixel a pixel, mesmo quando utilizada em imagens de média resolução. Fernandes et al. (2012), utilizando imagens Landsat, julgaram a classificação orientada a objetos como uma excelente ferramenta na classificação e delimitação das fitofisionomias do cerrado, auxiliando na tomada de decisões relacionadas ao manejo da paisagem.

A Bacia Rio da Prata, MS se destaca por apresentar características naturais de feições cársticas que apresentam fragilidades e potencialidades geoecológicas dos geossistemas calcários/cársticos (DIAS, 2000) e da exploração econômica do turismo na região.

Uma das atividades econômicas que expressam valor no domínio cárstico é o turismo, como ambientado em Bonito, MS e em diversas áreas cársticas brasileiras, devido à beleza cênica com cavernas, águas cristalinas, pontes e arcos rochosos (LOBO et al. 2007).

Paisagens cársticas constituem em áreas frágeis, onde pequenas alterações ambientais representam ameaças graves à integridade do meio subterrâneo. Atividades antrópicas como desmatamento, urbanização, zonas industriais, turismo em massa, entre outros, acarretam em impactos potenciais a essas áreas. De acordo com Gomes (2010) as 
características hidrológicas do terreno cárstico são mais suscetíveis às alterações no ambiente provocadas pela interferência antrópica, como as contaminações por materiais poluentes, pois a água se desloca de forma acelerada, podendo atingir expressiva extensão já que as características do terreno permitem a percolação da água nos complexos sistemas hidrológicos subterrâneos (AULER et al., 2011).

Diante desse contexto, o presente trabalho visa analisar as alterações oriundas das ações antrópicas no uso da terra da bacia do Rio da Prata - MS, utilizando técnicas de sensoriamento remoto e geoprocessamento, com intuito de expandir a base de conhecimentos, que poderão ser úteis para políticas públicas, na gestão do turismo e no ordenamento ambiental do território, configurando-se assim, como estratégia necessária de uso sustentável para essa paisagem cárstica.

\section{ÁREA DE ESTUDO}

A bacia do Rio da Prata está localizada numa área de paisagens particulares, conforme Dias (2000), tratando-se de uma área de contato de diferentes tipos e grupos litológicos e com intensos processos tectônicos. A região apresenta feições cársticas, resultado da litologia de rochas carbonáticas - calcários e dolomito- submetidas a sistemas morfoclimáticos úmidos, das Formações Cerradinho e Bocaina, do Grupo Corumbá no topo, e rochas do Grupo Cuiabá, na base, arcabouço geológico da Serra da Bodoquena (DIAS, 2000).

A área de estudo possui área de aproximadamente $1.305 \mathrm{~km}^{2}$, sendo que sua área de drenagem abrange os municípios de Bonito, Jardim e Porto Murtinho, no estado do Mato Grosso do Sul, constituindo uma área de atração turística devido a beleza ambiental oferecida (Figura 1) sendo que suas nascentes estão situadas no Parque Nacional da Serra da Bodoquena desaguando em sua foz no rio Miranda.

Com suas nascentes na Serra da Bodoquena, a bacia do Rio da Prata possui atrativos turísticos resultantes de relevo cárstico e rochas carbonáticas e que favorecem a formação de tufas calcária. A deposição de tufas na região está associada ao alto teor de carbonato de cálcio dissolvido na água, à alta limpidez da água, intensa atividade biológica e clima favorável. Essa deposição cobre as margens e os canais sobre o material rochoso, restos vegetais e construções ao longo dos principais vales fluviais, sendo que ao longo do Rio da Prata estão os depósitos mais extensos com 144 km². (SALLUN FILHO et al., 2009).

De acordo com o SILVA et al. (2011), essa área de depósitos de tufas na bacia do Rio da Prata, possui importância e prioridade extremamente alta, em relação a biodiversidade, devido aos rios cristalinos em substrato calcário. 
Figura 1 - Localização da área de estudo.

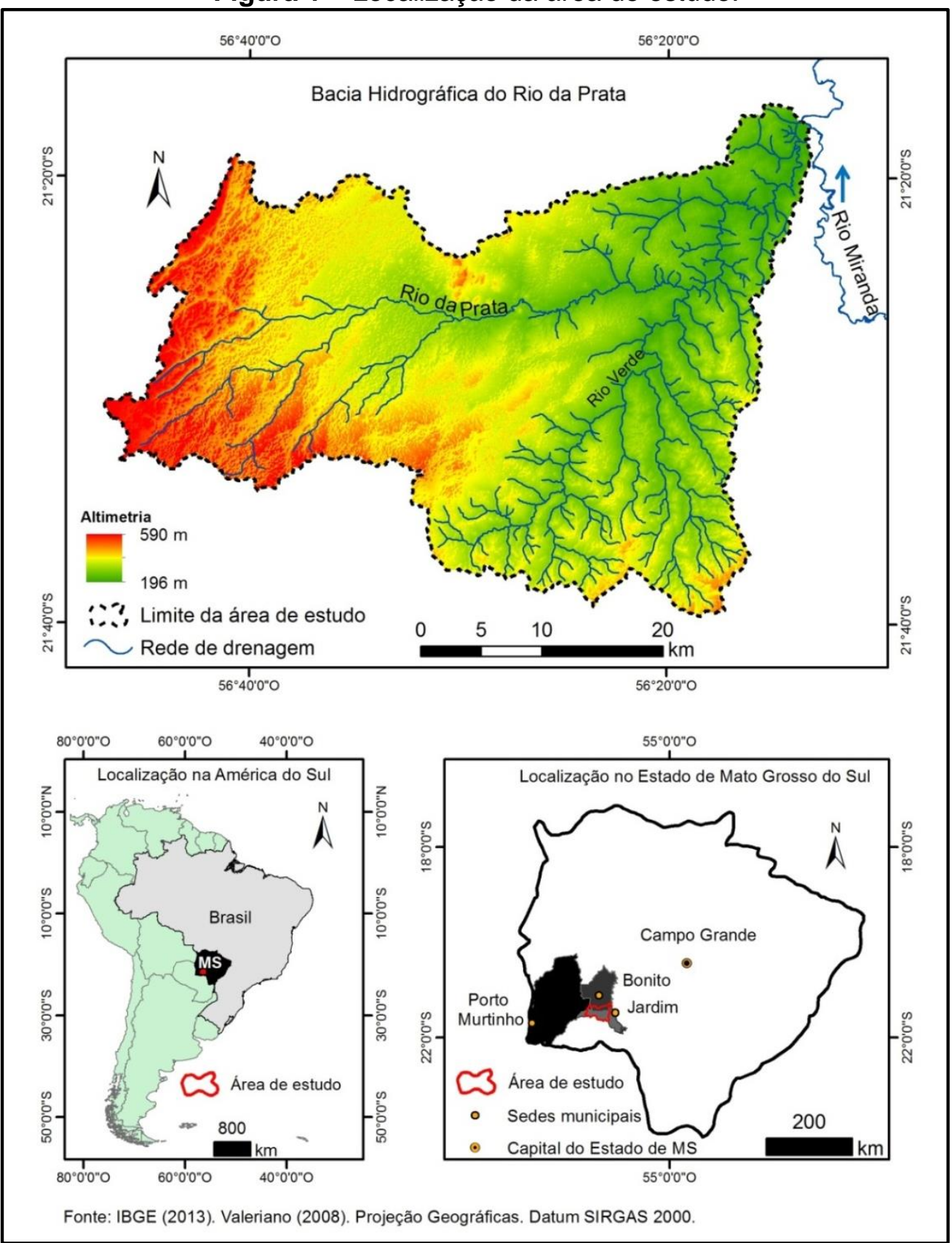

Fonte: Os autores.

A bacia do Rio da Prata entrecorta as unidades geológicas da Formação Aquidauana, estando na foz da bacia, e a Formação Xaraiés que se pronuncia em suas nascentes, na Serra da Bodoquena. A Formação Aquidauana é composta por um espesso pacote sedimentar, com litologias essencialmente arenosa e típica cor vermelha (GESICKI, 1997), sendo embasada por carbonatos dos Grupos Cuiabá e Corumbá, de idade proterozoica (SALLUN FILHO e KARMANN, 2007). A Formação Xaraiés representa um depósito de tufas calcárias, sendo que seu processo de sedimentação parece ter cessado há algum tempo, provavelmente em período anterior ao Holoceno (CORREA, 2006). 
De acordo com a EMBRAPA (2009), os solos da bacia são: Cambissolo Háplico Tb Distrófico Típico (Cxbd), Plintossolo Háplico Distrófico (FXd), Gleissolo Háplico Carbonático (Gxk), Gleissolo Háplico Ta Eutrófico (Gxve), Latossolo Vermelho Distrófico (Lvd), Chernossolo Rendzico Órtico (Mdo), Chernossolo Argilúvico Órtico (Mto), Nitossolo Vermelho Distrófico (Nvd), Nitossolo Vermelho Eutrófico (Nve), Argissolo Vermelho Distrófico (Pvd), Neossolo Litólico Eutrófico (Rle) e Neossolo Regolítico Eutrófico (RRe).

A topografia varia entre $196 \mathrm{~m}$ e $590 \mathrm{~m}$, com amplitude altimétrica de $394 \mathrm{~m}$, estando as maiores declividades nas nascentes da bacia, onde se localiza o Parque Nacional da Serra da Bodoquena, com classes que variam de 12 a mais de $50 \%$ de declividade. No restante da bacia, a declividade varia de 0 a $12 \%$.

Os cursos d'água apresentam-se superficialmente, ora subsuperficialmente, em alguns cursos, indicando a recente formação geológica do relevo cárstico, como indica Dias (2000) ao explicar que o carste existente na área possui certa juventude, pois ainda não está totalmente desenvolvido, com drenagem predominantemente superficial.

\section{MATERIAIS E MÉTODOS}

A base cartográfica, como a drenagem, a geologia (SILVA et al., 2011), geomorfologia (PCBAP, 2006), os solos (EMBRAPA, 2009) e a declividade (imagem de radar com 12,5 de resolução Advanced Land Observing Satellite (ALOS) Phased Arrayed type LBand SAR (PALSAR) (JAXA, 2017) foram trabalhadas no software ArcGIS 10.3 nos formato raster (.tiff) e vetorial (shapefile). As imagens de satélite foram selecionadas no banco de dados da USGS (United State Geological Survey, 2016), sendo utilizadas as imagens do satélite Landsat 5 referentes a 07/08/1986, 02/08/1996/ 13/07/2006 e do satélite Landsat 8 OLI referente a 24/07/2016, com 30 m de resolução multiespectral e 15 m na banca pancromática, sendo todas as imagens georreferenciadas.

As imagens Landsat passaram por processamento de calibração radiométrica, assim como correção atmosférica pelo módulo FLAASH (Fast Line-of-sight Atmospheric Analysis of Spectral Hypercubes), utilizando os algoritmos mais avançados (MODTRAN) do aplicativo ENVI 5.1.

No software Ecogntion Developer 9.2, a partir da abordagem de classificação orientada a objeto (GEOBIA - Geographic Object-Based Image Analysis), foi feita a composição colorida para cada imagem e segmentada utilizando o algoritmo multiresolution segmentation, para criação do tamanho apropriado dos objetos presentes na imagem, separando cada feição da paisagem. Os parâmetros de forma e compacidade dos objetos utilizados para cada imagem estão relacionados na Tabela 1. O campo forma, que varia de 
0 a 1, modifica a relação entre os critérios de homogeneidade espacial e informação espectral e a compacidade modifica os critérios de contorno (PIAZZA e VIBRANS, 2014).

Tabela 1 - Tipos de atributos pela ferramenta multiresolution segmentation

\begin{tabular}{l|l|l|l}
\hline & Escala & Forma & Compacidade \\
\hline $\mathbf{1 9 8 6}$ & 1 & 0.00005 & 0.003 \\
\hline $\mathbf{1 9 9 6}$ & 0.8 & 0.00005 & 0.0003 \\
\hline $\mathbf{2 0 0 6}$ & 1 & 0.00005 & 0.0003 \\
\hline $\mathbf{2 0 1 6}$ & 1 & 0.00005 & 0.5 \\
\hline
\end{tabular}

Fonte: Os autores.

Foram criadas as classes: agricultura, corpos aquosos, florestal, pastagem, áreas úmidas, vegetação arbórea e reflorestamento (somente para o ano de 2016) com base em interpretação visual das imagens e visitas a campo. Definiram-se os atributos para maior separabilidade entre as classes de classificação, na ferramenta Edit Standard Nearest Neighbor Feature Space (Tabela 2):

Tabela 2 - Tipos de atributos pela ferramenta Standard Nearest Neighbor Feature Space

\begin{tabular}{l|l}
\hline Feições dos objetos & Tipos de feições \\
\hline \multirow{2}{*}{ Valores de camada } & $\begin{array}{l}\text { Média de todos os valores de bandas, brilho e } \\
\text { diferença máxima, desvio padrão de todos os } \\
\text { valores de banda. }\end{array}$ \\
\hline \multirow{3}{*}{ Geometria } & $\begin{array}{l}\text { Extensão (área e comprimento / largura), forma } \\
\text { (compacidade e arredondamento), com base em } \\
\text { polígonos (número de arestas (polígono) e } \\
\text { desvio padrão de comprimento de arestas } \\
\text { (polígono)). }\end{array}$ \\
\hline Personalizado & NDVI e NDWI \\
\hline & Fonte: Os autores.
\end{tabular}

Depois de classificados os mapas de uso do solo dos anos de 1986, 1996, 2006 e 2016 foram exportados para o Envi 5.1 para a validação, sendo utilizados pontos analisados em campo e imagens de satélite Landsat 5 e 8 OLI, totalizando 385 pontos, calculados com erro amostral de 5\%, nível de confiança 95\% (SANTOS, 2014). O número de pontos foi definido de acordo com a área da bacia e distribuiu-se proporcionalmente e aleatoriamente nas classes de acordo com a área ocupada.

De acordo com Foody (2001), no mapeamento temático de imagens de sensoriamento remoto, a acurácia é utilizada para expressar o grau de correção de um mapa ou classificação. A estatística de Kappa é uma ferramenta estatística aplicada na avaliação da precisão de classificação de dois classificadores (FITZGERALD e LEES, 1994). O índice Kappa foi utilizado na avaliação das imagens classificadas e analisadas de acordo com os intervalos de Landis \& Koch (1977). 


\section{RESULTADOS E DISCUSSÃO}

Para analisar as mudanças no uso da terra na bacia do Rio da Prata, foram gerados os mapas de uso nos anos de 1986, 1996, 2006 e 2016, sendo possível quantificar as áreas de cada classe durante os anos estudados.

A categoria Florestal, que compreende as áreas de Floresta (cerradão), Floresta Estacional Decidual Submontana, Savana (cerrado) com floresta galeria e Floresta + Arborizada (SILVA et al., 2011) indicou uma manutenção da classe ao longo das quatro décadas estudadas. Em 1986, a classe apresentou 26,42\%, em 1996 houve um pequeno decréscimo, com 25,18\%, em 2006 a classe possuía $27,23 \%$ e em 2016 ocupava área de $27,96 \%$, indicando que, em sua maioria, as áreas de mata galeria e na região do Parque Nacional da Serra da Bodoquena, a montante da bacia, estão preservadas (Tabela 3).

Tabela 3 - Quantificação das classes de uso da terra da bacia hidrográfica do Rio da Prata (área).

\begin{tabular}{l|l|l|l|l|l|l|l|l}
\hline \multirow{2}{*}{$\begin{array}{l}\text { Classes de } \\
\text { uso }\end{array}$} & $\mathbf{1 9 8 6}$ & $\mathbf{1 9 9 6}$ & $\mathbf{2 0 0 6}$ & $\mathbf{2 0 1 6}$ \\
\cline { 2 - 9 } & $\mathbf{k m}^{\mathbf{2}}$ & $\mathbf{\%}$ & $\mathbf{k m}^{\mathbf{2}}$ & $\mathbf{\%}$ & $\mathbf{k m}^{\mathbf{2}}$ & $\mathbf{\%}$ & $\mathbf{k m}^{\mathbf{2}}$ & $\%$ \\
\hline Agricultura & 73,31 & 5,27 & 51,02 & 3,66 & 66,53 & 4,78 & 117,89 & 8,47 \\
\hline $\begin{array}{l}\text { Corpos } \\
\text { aquosos }\end{array}$ & 2,59 & 0,19 & 2,25 & 0,16 & 1,87 & 0,13 & 3,31 & 0,24 \\
\hline Florestal & 367,83 & 26,42 & 350,57 & 25,18 & 379,15 & 27,23 & 389,14 & 27,96 \\
\hline Pastagem & 419,13 & 30,10 & 559,52 & 40,18 & 663,43 & 47,66 & 601,32 & 43,21 \\
\hline $\begin{array}{l}\text { Áreas } \\
\text { úmidas }\end{array}$ & 70,93 & 5,09 & 98,68 & 7,09 & 77,92 & 5,60 & 117,77 & 8,46 \\
\hline $\begin{array}{l}\text { Vegetação } \\
\text { arbórea }\end{array}$ & 458,44 & 32,93 & 330,46 & 23,73 & 203,25 & 14,60 & 160,90 & 11,56 \\
\hline $\begin{array}{l}\text { Refloresta } \\
\text { mento }\end{array}$ & - & - & - & - & - & - & 1,31 & 0,09 \\
\hline $\begin{array}{l}\text { Total das das } \\
\text { classes }\end{array}$ & 1392,22 & 100,00 & 1392,50 & 100,00 & 1392,15 & 100,00 & 1391,64 & 100,00 \\
\hline
\end{tabular}

Fonte: Os autores.

Já a classe Vegetação arbórea, que compreende uma vegetação com porte menor, a Arborizada + Gramíneo Lenhosa e Savana Gramíneo Lenhosa (campo), apresentou um decréscimo significativo. No ano de 1986, a classe aparecia com 32,93\% de área ocupada, em 1996 decai para 23,73\%, em 2006 para 14,60, e em 2016, ocupa apenas 11,56\% de área. Essa categoria de uso apresenta-se distribuída, em maior extensão, próxima a categoria Florestal, em áreas de mata ciliar, próximas aos cursos d'água.

A classe Agricultura em 1996 ocupa 5,27\% de área, em 1996 perde espaço para a Pastagem, ocupando 3,66\%, em 2006 sobe para 4,78\% e em 2016 apresenta $8,47 \%$ de 
área. De acordo com o IBGE cidades (2015) as lavouras temporárias de mandioca, cana, milho e soja constituem essa categoria na região (Figura 2).

Figura 2 - Uso da terra na bacia hidrográfica do Rio da Prata em 1986.

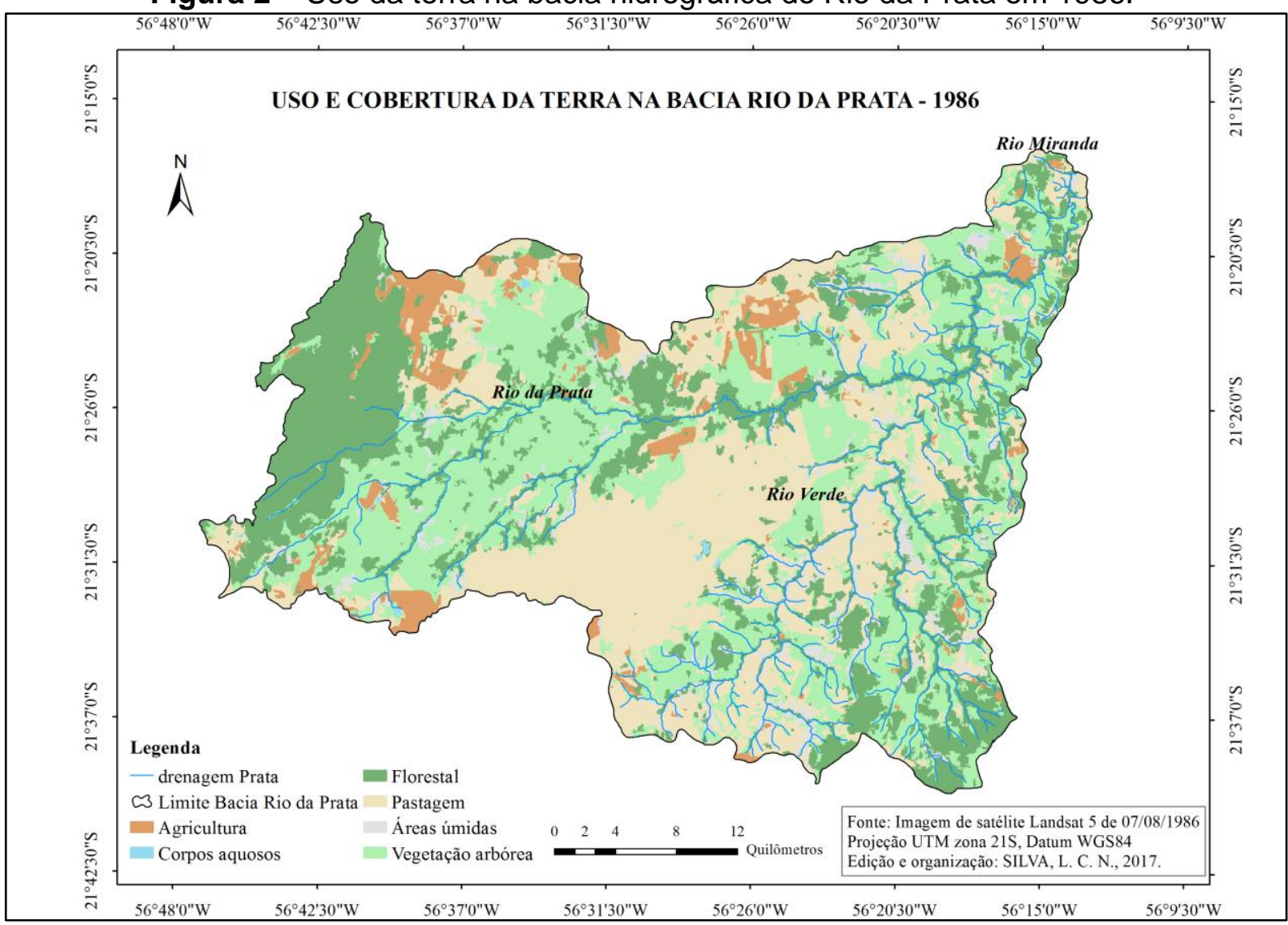

Fonte: Os autores.

As áreas de corpos aquosos e áreas úmidas apresentaram diferenças ao longo dos anos, possivelmente por fatores climáticos, indicando períodos de mais ou menos chuvas. Os corpos aquosos representam os canais de drenagem e dolinas. Conforme Sallun Filho, et al. (2004) as dolinas, nascentes e cones cársticos são feições relativamente comuns tanto no Planalto da Bodoquena quanto na Depressão do Rio Miranda (Figura 3):

A Pastagem, categoria que apresenta maior expressão em área ocupada na bacia, apresenta um aumento entre 1986 (30,10\%), 1996 (40,18\%), 2006 (47,66\%) (Figura 4), porém em 2016 há um decréscimo (43,21\%), indicando a expansão da agricultura, além da classe Reflorestamento $(0,09 \%)$, que é pouca expressiva, porém apresenta área ocupada em 2016.

Nas nascentes do Rio Verde, afluente do Rio da Prata, há alta densidade estando relacionadas à Formação Aquidauana, com solos Argissolos e Latossolos, em relevos relativamente dissecados. As retiradas da vegetação arbórea aliada à ausência de práticas 
conservacionistas favorecem a supressão da camada superficial desses solos, já que os solos dessa área, no caso o Argissolo, possui como característica nítida diferenciação textural entre os horizontes A e B (textural).

Figura 3 - Uso da terra na bacia hidrográfica do Rio da Prata em 1996.

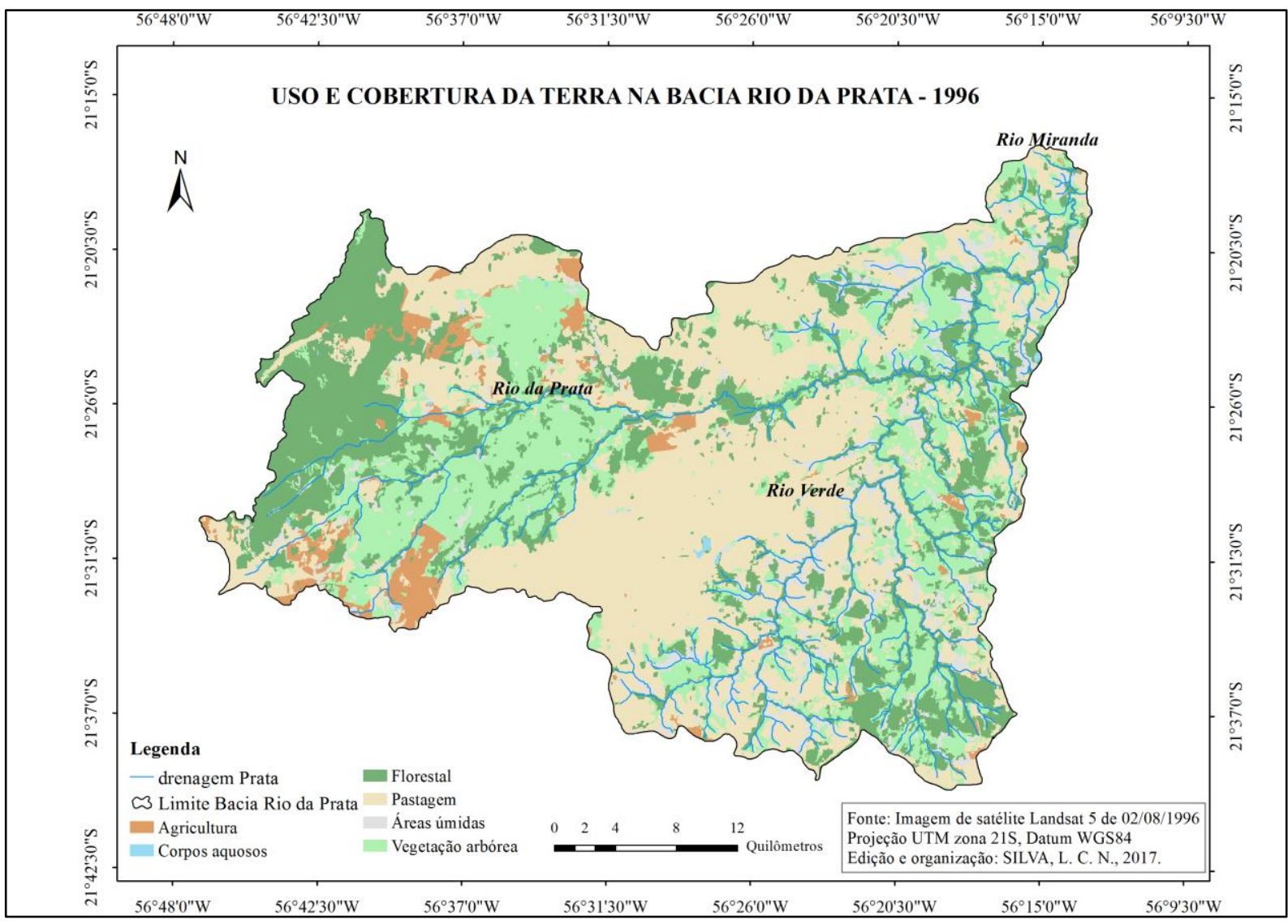

Fonte: Os autores.

No alto e médio curso da bacia, distribuem-se os tipos de solos: Cambissolos, Chernossolo, Plintossolo, Gleissolo, Nitossolo, Neossolo, ou seja, solos em sua maioria menos espessos, resultado da alteração da rocha calcária subjacente. Em material de calcário puro, o solo torna-se menos espesso, já que os solos formados em ambiente cárstico são resultados das impurezas em meio aos minerais formadores da rocha (HARDT, 2004).

Piló (2000) salienta ainda que os solos calcários apresentam maior tempo para formação do que os solos provenientes de rochas carbonáticas, indicando a importância da conservação das classes de vegetação para desenvolvimento pedogenético e integridade do meio subterrâneo.

A Figura 5 mostra o uso da terra no ano de 2016, sendo possível analisar a expansão do pasto e da agricultura e a redução da vegetação arbórea. 
Figura 4 - Uso da terra na bacia hidrográfica do Rio da Prata em 2006.

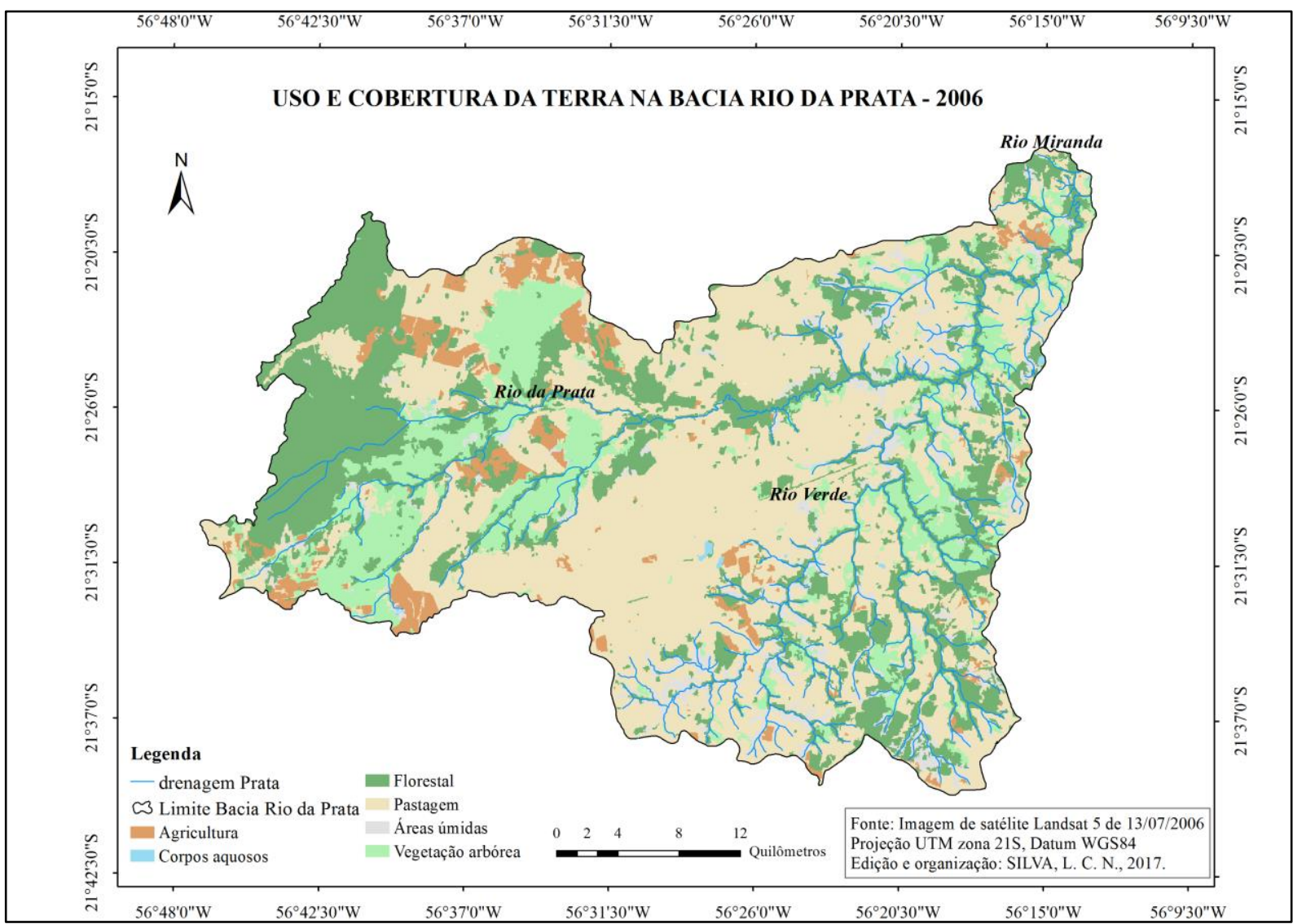

Fonte: Os autores.

A partir dos pontos de verdade terrestres e de uso do solo dos mapas, foi possível elaborar a matriz de confusão, com resultados de 0,86\% de índice Kappa e acurácia global de 90,15\% para 1986, 0,85\% de índice Kappa e acurácia global de 89,11 para 1996, 0,80\% de índice Kappa e acurácia global de 86,01\% para 2006 e 0,82\% de índice Kappa e acurácia global de 87,30\% para 2016 (Tabela 4).

O pior valor de acurácia observado foi do produtor, com $50 \%$ na classe de vegetação arbórea, em 2016 e maior valor, de 100\% na classe florestal do produtor em 1986; 100\% do usuário em corpos aquosos no ano de 1996, 2006 e 2016, e 100\% do usuário na classe de reflorestamento em 2016. De acordo com a classificação de Landis \& Koch (1977), permite considerar os resultados dos níveis do índice Kappa como substancial a quase perfeita.

Os resultados mostraram ser parecidos aos de Hentz et al. (2015) que obtiveram o índice Kappa de 0,8 e confusão global de 0,88, utilizando imagens de satélite Landsat 8 e classificação orientada a objeto para o ano de 2013, considerando três classes de uso. Marujo et al (2013) utilizaram cinco classes de uso em imagens de alta resolução, do sensor RE-4, acoplado aos satélites REIS (RapidEye imaging system) e obteve índice Kappa de 0,80305 e índice global de 0,87536. 
Figura 5 - Uso da terra na bacia hidrográfica do Rio da Prata em 2016.

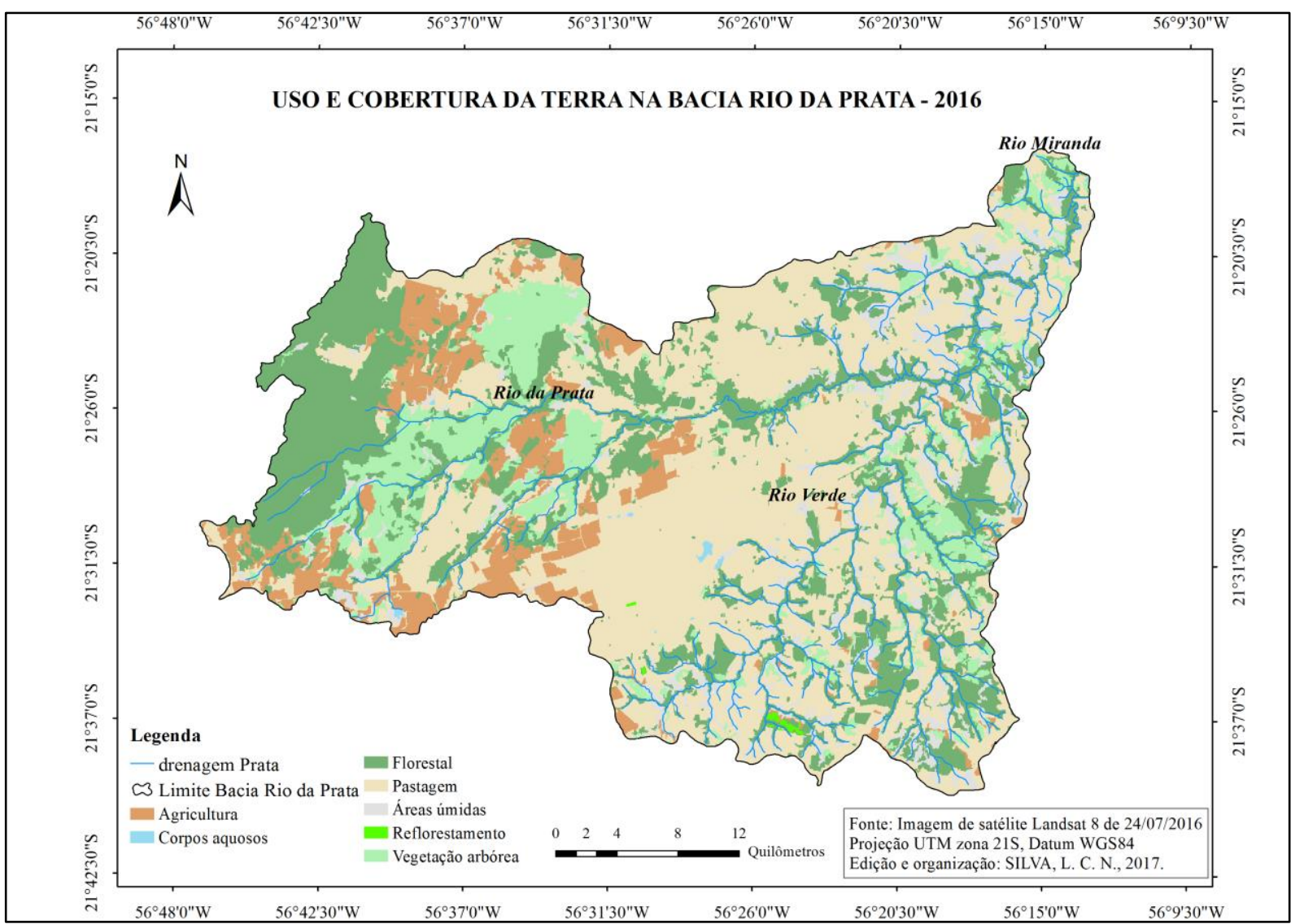

Fonte: Os Autores.

Tabela 4 - Acurácia dos mapas de uso da terra da bacia hidrográfica do Rio da Prata.

\begin{tabular}{|c|c|c|c|c|c|c|c|c|}
\hline \multirow[b]{2}{*}{$\begin{array}{l}\text { Classes de } \\
\text { uso }\end{array}$} & \multicolumn{2}{|l|}{1986} & \multicolumn{2}{|l|}{1996} & \multicolumn{2}{|l|}{2006} & \multicolumn{2}{|l|}{2016} \\
\hline & $\begin{array}{l}\text { Produto } \\
\text { r Acc. } \\
\text { (\%) }\end{array}$ & $\begin{array}{l}\text { Usuári } \\
\text { o Acc. } \\
(\%)\end{array}$ & $\begin{array}{l}\text { Produto } \\
\text { r Acc. } \\
\text { (\%) }\end{array}$ & $\begin{array}{l}\text { Usuári } \\
\text { o Acc. } \\
\text { (\%) }\end{array}$ & $\begin{array}{l}\text { Produto } \\
\text { r Acc. } \\
(\%)\end{array}$ & $\begin{array}{l}\text { Usuári } \\
\text { o Acc. } \\
(\%)\end{array}$ & $\begin{array}{l}\text { Produto } \\
\text { r Acc. } \\
(\%)\end{array}$ & $\begin{array}{l}\text { Usuári } \\
\text { o Acc. } \\
\text { (\%) }\end{array}$ \\
\hline Agricultura & 88,24 & 90,91 & 91,18 & 96,88 & 88,24 & 85,71 & 88,24 & 83,33 \\
\hline $\begin{array}{l}\text { Corpos } \\
\text { aquosos }\end{array}$ & 90,91 & 90,91 & 90,91 & 100,00 & 90,91 & 100,00 & 90,91 & 100,00 \\
\hline Florestal. & 100,00 & 93,52 & 97,03 & 93,33 & 98,02 & 90,83 & 98,02 & 86,84 \\
\hline Pastagem & 92,86 & 95,91 & 94,16 & 96,03 & 94,16 & 89,51 & 94,81 & 91,82 \\
\hline Áreas úmidas & 61,90 & 96,30 & 61,90 & 81,25 & 52,38 & 75,86 & 70,97 & 73,33 \\
\hline $\begin{array}{l}\text { Reflorestament } \\
0\end{array}$ & - & - & - & - & - & - & 72,73 & 100,00 \\
\hline $\begin{array}{l}\text { Vegetação } \\
\text { arbórea }\end{array}$ & 86,36 & 65,52 & 77,27 & 60,71 & 59,09 & 63,41 & 50,00 & 78,57 \\
\hline $\begin{array}{l}\text { Acurácia } \\
\text { Total } \\
(\%)\end{array}$ & 90,15 & & 89,11 & & 86,01 & & 87,30 & \\
\hline $\begin{array}{l}\text { Coeficiente } \\
\text { Kappa }\end{array}$ & 0,86 & & 0,85 & & 0,80 & & 0,82 & \\
\hline
\end{tabular}

Fonte: Os autores. 


\section{CONCLUSÃO}

Utilizando técnicas de sensoriamento remoto e geoprocessamento, a partir da abordagem de classificação orientada a objeto, foi possível analisar as mudanças no uso e cobertura da terra na bacia do Rio da Prata, MS que podem acarretar em significativas alterações na paisagem cárstica da região.

De acordo com os resultados dos mapas de uso ao longo dos anos de 1986, 1996, 2006 e 2016, é possível analisar que a bacia apresenta expansão agropecuária em detrimento da vegetação arbórea (Arborizada + Gramíneo Lenhosa e Savana Gramíneo lenhosa (campo)).

Devido a fragilidade ambiental apresentada no relevo cárstico, o desmatamento associados à falta de práticas conservacionistas favorecem a degradação ambiental, sendo de extrema importância estudos como o de zoneamento ambiental, que assegurem que sejam preservadas as estruturas ambientais, e que as áreas de atividades antrópicas, com usos intensivos e extensivos, associados ao turismo, sejam adequadas em zonas que não venham a ameaçar o equilíbrio ecológico.

Foi considerado satisfatório o resultado do coeficiente Kappa nas imagens de satélite Landsat 5 e $8 \mathrm{OLI}$, com classificação orientada a objeto, considerando as imagens orbitais de média resolução espacial.

\section{AGRADECIMENTO}

Agradecemos à CAPES pela concessão de bolsa PNPD de estágio em pósdoutorado à primeira autora, à FUNDECT pelo apoio financeiro ao projeto de pesquisa da Chamada FUNDECT/CAPES N 12/2015 - BIOTA-MS - CIÊNCIA E BIODIVERSIDADE, processo no.59/300.140/2016 e à UFMS-Campus de Três Lagoas pela acolhida no Laboratório de Sensoriamento Remoto.

\section{REFERÊNCIAS BIBLIOGRÁFICAS}

AULER, A. S. et al. III Curso de Espeleologia e Licenciamento Ambiental. ICMBio Instituto Chico Mendes de Conservação da Biodiversidade , CECAV - Centro Nacional de Pesquisa e Conservação de Cavernas. 2011. Belo Horizonte 197p. Disponível em: $<$ http://www.terrabrasilis.org.br/ecotecadigital/pdf/apostilacursodeespeleologia.pdf $>$. Acesso em 09/03/2016.

BLASCHKE, T. et al. / ISPRS Journal of Photogrammetry and Remote Sensing 87 (2014). p. 180-191.

CORREA, D. Caracterização, Cronologia e Gênese das Tufas da Serra das Araras Mato Grosso. 2006. 117 f. Dissertação. (Mestrado em Geografia). Universidade Federal de Minas Gerais Departamento de Geografia. Belo Horizonte, MG. 
DESCLÉE, B., BOGAERT, P., DEFOURNY, P., Forest change detection by statistical object based method. Rev. Remote Sens. Environ. 2006.102, 1-11.

DIAS, J., - A região cárstica de Bonito/MS: uma proposta de zoneamento geoecológico a partir de unidades de paisagem. Disponível em:

$<w w w$.jailton.tripod.com/artigo arquivosljdbckg.ipg \& jailton.tripod.com/artigoagb.html>, 2000. Acesso em: 20 abr 2016.

EMBRAPA. Empresa Brasileira de Pesquisa Agropecuária. Geoportal Digital. Disponível em <http://mapoteca.cnps.embrapa.br/>. 2009.

FERNANDES, R. R. et al.. Classificação orientada a objetos aplicada na caracterização da cobertura da terra no Araguaia. Rev. Pesq. agropec. bras., Set 2012, vol.47, no.9, p.12511260.

FITZGERALD, R. W., e LEES, B. G. (1994). Assessing the classification accuracy of multisource remote sensing data. Rev. Remote Sensing of Environment, 47, 362 - 368.

FOODY, G. M. Status of land cover classification accuracy assessment. Rev. Elsevier Remote Sensing of Environment. V.80 (2002) 185- 201.

GESICKI, A. L. D. Geologia da Formação Aquidauana (Neopaleozóico, Bacia do Paraná) na formação centro-norte do estado de Mato Grosso do Sul. 1997. 162 f. Dissertação (Mestrado em Geologia Sedimentar). Universidade de São Paulo. Instituto de Geociências, São Paulo.

GOMES, M. Proposta metodológica para identificação de áreas vulneráveis para a conservação do patrimônio espeleológico brasileiro. 2010. 62 f. Monografia. Grau de especialista em geoprocessamento. Depto de Cartografia. Instituto de Geociências. Universidade Federal de Minas Gerais. Belo Horizonte.

HARDT, R. Aspectos da morfologia cárstica da Serra do Calcário - Cocalinho - MT. 2004. 98 f. Dissertação (Mestrado em Organização do Espaço). Universidade Estadual Paulista, Rio Claro.

HENTZ, A. M. K. et al. Técnicas orientadas ao objeto para levantamento da fragmentação florestal na sub-bacia Alto Iguaçu, Paraná. Rev. Geociências São Paulo, UNESP, , v. 34, n. 4, p.883-896, 2015.

JAPAN AEROSPACE EXPLORATION AGENCY (JAXA). Disponível em:

http://www.eorc.jaxa.jp/ALOS/en/obs/palsar_strat.htm . Acesso em: 12 jan. 2017.

LANDIS, J.R.; KOCH, G.G. The measurement of observer agreement for categorical data.

Rev. Biometrics, Arlington, v. 33, p.159-174, 1977.

LOBO, H. A. S. et al. Potencial geoturístico da paisagem cárstica. Rev. Periódico de Turismo. Vol. 3, n. 2. Nov. 2007. P.1-20.

MARUJO, R. de F. B. Classificação orientada a objetos aplicada á cultivos cafeeiros em Três Pontas - MG. In: Anais XVI Simpósio Brasileiro de Sensoriamento Remoto SBSR, Foz do Iguaçu, PR, Brasil, 13 a 18 de abril de 2013, INPE.

PCBAP, Plano de conservação da bacia do alto Paraguai e o zoneamento ecológico econômico para o Brasil. In: Anais 1 Simpósio de Geotecnologias no Pantanal, Campo Grande, Brasil, 11-15 novembro 2006, Embrapa Informática Agropecuária/INPE, p.667-674.

PIAZZA, G. A. e VIBRANS, A. C. Classificação orientada a objetos para mapear florestas secundárias em Santa Catarina, sul do Brasil. Revista Brasileira de Cartografia, Rio de Janeiro, N0 66/5, p. 993-1005, Set/Out/2014.

PILÓ, L. B. Geomorfologia cárstica. Rev. Brasileira de Geomorfologia. V. 1 n.1 2000. P. 88-102. 
PLATT, R.V.; RAPOZA, L. An evaluation of an object-oriented paradigm for land use/land cover classification. The Professional Geographer, v.60, p.87-100, 2008.

SALLUN FILHO, W. e KARMANN I.. Dolinas em arenitos da Bacia do Paraná: evidências de carste subjacente em Jardim (MS) e Ponta Grossa (PR). Revista Brasileira de

Geociências. 37(3): 551-564, setembro de 2007. Arquivo digital disponível on-line no site www.sbgeo.org.br 551.

SALLUN FILHO, W. et al. A Deposição de Tufas Quaternárias no Estado de Mato Grosso do Sul: Proposta de Definição da Formação Serra da Bodoquena. Revista do Instituto de Geociências - USP. Geol. USP, Sér. cient., São Paulo, v. 9, n. 3, p. 47-60, outubro 2009.

SALLUN FILHO, W. et al. Paisagens Cársticas da Serra da Bodoquena. In: Geologia do continente Sul-americano: evolução da obra de Fernando Flávio Marques de Almeida, Chapter: XXV, Publisher: Ed. Beca, Editors: Virgínio Mantesso-Neto, Andrea Bartorelli, Celso Dal Ré Carneiro, Benjamin Bley de Brito-Neves, 2004. p.424-433.

SANTOS, G. E.o de O. Cálculo amostral: calculadora on-line. Disponível em: <http://www.publicacoesdeturismo.com.br/calculoamostral/ . Acesso em: 20/04/2017.

SISLA. Sistema Interativo de Suporte ao Licenciamento Ambiental. Disponível em: $<$ http://sisla.imasul.ms.gov.br/sisla/pagina inicial.php>. Acesso em: 13/10/2016.

United States Geological Survey (USGS). Landsat Project Description. Disponível em: <https://landsat.usgs.gov/>. Acesso em: 19 set 2016.

\footnotetext{
${ }^{1}$ Laís Coêlho do Nascimento Silva. Pós-doutoranda do Programa de Pós graduação em Geografia da Universidade Federal do Mato Grosso do Sul - UFMS, Campus de Três Lagoas. Endereço profissional: Ranulpho Marques Leal, 3484 / CEP 79613-000 / Cx Postal n210. Email: lais cns@yahoo.com.br

${ }^{2}$ Vitor Matheus Bacani. Professor Adjunto da Universidade Federal de Mato Grosso do Sul - UFMS, Campus de Três Lagoas. Endereço profissional: Ranulpho Marques Leal, 3484 / CEP 79613-000 / Cx Postal n210. Email: vitormbacani@gmail.com
} 